\title{
Penerapan Algoritma Algoritma Boyer Moore untuk Penyaringan Pesan dan Algoritma Hill Cipher dalamKeamanan Pesan Teks Berbasis Web Chat
}

\author{
Tomy Satria Alasi \\ STMIK Budi Darma, Jl. Sisingamangaraja No.338 Simpang Limun Medan
}

\begin{tabular}{|c|}
\hline ARTICLE INFORMATION \\
\hline $\begin{array}{l}\text { Received: Agustus } 28,2019 \\
\text { Revised: September } 22,2019 \\
\text { Available online: Oktober } 05,2019\end{array}$ \\
\hline KEYWORDS \\
\hline $\begin{array}{l}\text { Web Chat, Pesan Teks, Penyaringan Pesan, } \\
\text { Keamanan Pesan, Algoritma Boyer Moore, } \\
\text { Algoritma Hill Cipher }\end{array}$ \\
\hline CORRESPONDENCE \\
\hline Phone: +6282275847123 \\
\hline E-mail: tomysatriaalasi@gmail.com \\
\hline
\end{tabular}

\begin{abstract}
A B $\mathbf{S}$ T $\mathbf{R}$ A $\mathbf{K}$
Web chat merupakan halaman situs untuk saling berbagi informasi komunikasi melalui pesan teks, suara, vidio dan file yang dapat diakses dengan masuk ke dalam sistem aplikasi yang disediakan oleh situs. Khusus untuk berbagi pesan teks melalu web chat sering berisi kata-kata yang tidak baik sehingga hal-hal yang tidak diinginkan terjadi seperti saling membalas kata-kata yang tidak baik bahkan berahir dengan perkelahian dan penyedia juga kurang memperhatikan keamanan dalam proses pesan teks sehingga pesan mudah dibajak oleh orang yang tidak berkepentingan dengan macam-macam tujuan, dua permasalahan tentu tidak diinginkan oleh seseorang pada saat berbagi pesan. Dengan segala permasalahan yang diuraikan ternyata ada suatu penyelesaian masalah tersebut yaitu dengan memanfaatkan algoritma boyer moore yaitu proses pencarian kata dari kanan karakter ke kiri karakter sehingga proses pencarian tek pada kata lebih cepat sehingga tidak ada yang terlewatkan dari teks sampai menumukan kata yang tidak pantas dan disaring atau disembunyikan dan memakai algoritma hill cipher dengan penyandian hingga perubahan pada pesan teks dengan proses aritmatika matriks sehingga kunci dan pembuka tidak sama dan susah dipecahkan sekalipun karakter pada teks sama. Sehingga dengan mengunakan dua algoritma tersebut yaitu algoritma boyer moore dan algoritma hill cipher dua permasalahan tersebut dapat diselesaikan yaitu penyaringan pesan teks dan pengamanan pesan teks.
\end{abstract}

\section{PENDAHULUAN}

Pesan merupakan suatu informasi yang dapat dibaca dan dimengerti maknanya agar pesan dapat diterima dari pengguna satu ke pengguna lain, proses pengiriman pesan memerlukan sebuah media perantara agar pesan yang dikirimkan oleh sumber (source) dapat diterima dengan baik oleh penerima (receiver). Perkembangan teknologi jaringan komputer menyebabkan terkaitnya satu komputer dengan komputer lainnya menjadi lebih mudah untuk berbagi pesan dan informasi mulai dari perusahaan, organisasi dan bahkan hanya untuk bercerita antar seseorang, tanpa disadari hampir setiap hari orang-orang melakukan proses berbagi pesan sehingga pesan menjadi inti dari setiap proses komunikasi yang terjadi. Proses pengiriman pesan harus dikemas sebaik mungkin untuk mengatasi gangguan yang muncul dalam transmisi pesan, agar tidak mengakibatkan perbedaan makna yang diterima oleh penerima[1], [2].

Web chat adalah sistem yang memungkinkan pengguna untuk berkomunikasi secara real time dengan menggunakan antarmuka web yang mudah diakses, merupakan jenis internet chat online dengan kesederhanaan dan aksesibilitas bagi pengguna yang ingin meluangkan waktu berbagi komunikasi[3].

Penyaringan pesan yang tepat sehingga pesan yang telah terkim diperiksa atau disaring secara keseluruhan bila menemukan kata-kata yang tidak pantas akan di sembunyikan dan digantikan dengan karakter tertentu sehingga kalimat dipesan teks tersebut memiliki kata-kata yang sopan, baik dan dewasa sehingga antara pengirim dan penerima tidak akan ada pertengkaran didalam berbagi pesan melalui aplikasi web chat tersebut. Penyedia web chat kurang memperhatikan keamanan dalam proses pesan teks network, seseorang bisa saja dengan ilegal melihat isi pesan tersebut tanpa diketahui pengirim atau penerima. Sehingga tanpa fasilitas keamanan penerima akan menerima pesan tersebut dengan adanya perubahan hal tersebut pasti tidak diinginkan oleh siapapun sekalipun pesan tersebut hanya sebatas saling menyapa[4].

\section{LANDASAN TEORI}

\section{a. Kriptografi}

Kriptografi adalah sebuah ilmu yang mempelajari teknik-teknik matematika yang berhubungan dengan aspek keamanan informasi seperti kerahasiaan, integritas data serta otentikasi[5][6]. Hill cipher diciptakan oleh Lester S. Hill pada tahun 1929.Teknik kriptografi ini diciptakan dengan maksud untuk dapat menciptakan cipher (kode) yang tidak dapat dipecahkan menggunakan teknik analisis frekuensi. Hill cipher tidak mengganti setiap abjad yang sama pada plaintext dengan abjad lainnya yang sama pada ciphertext karena menggunakan perkalian matriks pada dasar enkripsi dan dekripsinya. Hill cipher adalah kriptografi simetris biasa juga disebut kode hill merupakan penerapan aritmatika modulo pada kriptografi. Teknik kriptografi ini menggunakan sebuah matriks persegi sebagai kunci yang digunakan untuk melakukan enkripsi dan dekripsi[7]. 


\section{b. Algoritma Boyer Moore}

Pencocokan string merupakan bagian penting dari sebuah proses pencarian string (string searching) dalam sebuah dokumen. Hasil dari pencarian sebuah string dalam dokumen tergantung dari teknik atau cara pencocokan string yang digunakan. Untuk mengetahu isi dokumen yang benar sesuai dengan kebutuhan informasi, diperlukan metode pencarian string (string searching) isi dokumen yang bagus. Proses pencocokan string (string matching) yang merupakan bagian utama dalam proses pencarian string memegang peranan penting untuk mendapatkan dokumen yang sesuai dengan kebutuhan informasi[8].

Algoritma boyer moore menjadikan dalam pencarian lebih cepat dibandingkan algoritma-algoritma pencocokkan kata lainnya. Dan juga banyak dikembangkan algoritma pencocokkan kata dengan bertumpu pada konsep algoritma boyer moore , seperti algoritma quick search. Konsep algoritma boyer moore adalah preprocessing, right to left scan, bad character shift, good suffix shift [9].

\section{c. Ajax Dan JQUERY}

Ajax adalah singkatan dari Asynchronous JavaScript and XML. Pada dasarnya ajax menggunakan XMLHttpRequest object Javascript untuk membuat request ke server secara asynchronous atau tanpa melakukan refresh halaman website. Yang dibutuhkan agar ajax dapat berjalan adalah javascript harus di enable pada browser yang digunakan. Walaupun javascript merupakan dasar dari Ajax, dimana javascript sangat sulit pada implementasi dan maintenance, tetapi Ajax memiliki struktur pemrograman yang lebih mudah untuk dipahami. Anda tinggal membuat object XMLHttpRequest dan memastikan object tersebut terbentuk dengan benar. Kemudian menentukan kemana hasilnya akan ditampilkan atau dikirim[10].

\section{HASIL DAN PEMBAHASAN}

\section{a. Pembentukan Web Chat}

Struktur web chat dengan keamanan dan penyaringan pesan sebagai berikut :

\section{Pesan Dikunci Pengirim}

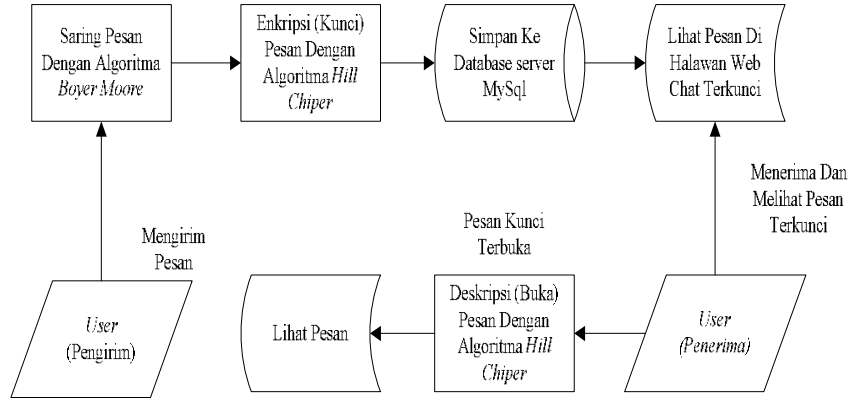

Gambar 1. Struktur Pembentukan Web Chat

Keterangan:

User $\quad$ : yaitu pengguna untuk menerima pesan atau mengirim pesan web chat.

Saring pesan : proses penyaringan pesan sebelum dienksripsi kemudian kemudian pesan dideksripsi oleh sistem dan disimpan di-database.

Enkripsi $\quad$ : yaitu untuk proses penyandian pesan teks yang akan dikirim atau disimpan kedatabase.

Database Server : proses penyimpanan pesan teks, detail pesan teks, serta menjadi sumber penerimaan pesan kepada penerima sesuai pengiriman pesan ditujukan.

Deskripsi pesan : proses pengembalian pesan ke-teks asli berdasarkan kunci dan rumus yang telah ditetapkan.

\section{b. Algoritma Boyer Moore Untuk Penyaringan Pesan Teks}

Rumus: $\mathrm{BM}=\mathrm{T}($ text $+\mathrm{n}$ text -1$)=\mathrm{P}$

Dimana:BM $=$ Boyer moore, $\mathrm{T}=$ Text dan $\mathrm{P}=$ Pattert.

Diketahui: Text (S): RINDU KAMU JELEK, Pattern (P): JELEK.

Langkah Kerja :

1. Langkah Pertama

\begin{tabular}{|l|l|l|l|l|l|l|l|l|l|l|l|l|l|l|l|l|l|l|}
\hline T & & & & & R & I & N & D & U & & K & A & M & U & & J & E & L \\
\hline P & J & E & L & E & K & & & & & & & & & & & & \\
\hline
\end{tabular}

2. Langkah Kedua

\begin{tabular}{|c|c|c|c|c|c|c|c|c|c|c|c|c|c|c|c|}
\hline \begin{tabular}{|l|}
$\mathrm{T}$ \\
\end{tabular} & & & $\mathrm{R}$ & I & $\mathrm{N}$ & & $\mathrm{U}$ & \begin{tabular}{|l|}
$\mathrm{K}$ \\
\end{tabular} & $\mathrm{A}$ & & $\mathrm{U}$ & $\mathrm{J}$ & $\mathrm{E}$ & & E \\
\hline \begin{tabular}{|l|l}
$\mathrm{P}$ & $\mathrm{J}$ \\
\end{tabular} & $\mathrm{E}$ & $\mathrm{L}$ & E & $\mathrm{K}$ & & & & & & & & & & & \\
\hline
\end{tabular}

3. Langkah Ketiga

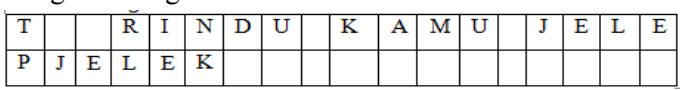

Penerapan Algoritma Algoritma Boyer Moore untuk Penyaringan Pesan dan Algoritma Hill Cipher dalam Keamanan 
4. Langkah Keempat

\begin{tabular}{|l|l|l|l|l|l|l|l|l|l|l|l|l|l|l|l|l|l|}
\hline T & & R & I & N & D & U & & K & A & M & U & & J & E & L & E & K \\
\hline P & J & E & L & E & K & & & & & & & & & & & & \\
\hline
\end{tabular}

5. Langkah Kelima

\begin{tabular}{|l|l|l|l|l|l|l|l|l|l|l|l|l|l|l|l|l|}
\hline T & R & I & N & D & U & & K & A & M & U & & J & E & L & E & K \\
\hline P & J & E & L & E & K & & & & & & & & & & & \\
\hline
\end{tabular}

6. Langkah Keenam

\begin{tabular}{|l|l|l|l|l|l|l|l|l|l|l|l|l|l|l|l|l|}
\hline T & R & I & N & D & U & & K & A & M & U & & J & E & L & E & K \\
\hline P & & J & E & L & E & K & & & & & & & & & & \\
\hline
\end{tabular}

7. Langkah Ketujuh

\begin{tabular}{|l|l|l|l|l|l|l|l|l|l|l|l|l|l|l|l|l|}
\hline T & R & I & N & D & U & & K & A & M & U & & J & E & L & E & K \\
\hline P & & & J & E & L & E & K & & & & & & & & & \\
\hline
\end{tabular}

8. Langkah Kedelapan

\begin{tabular}{|l|l|l|l|l|l|l|l|l|l|l|l|l|l|l|l|l|}
\hline T & R & I & N & D & U & & K & A & M & U & & J & E & L & E & K \\
\hline P & & & & J & E & L & E & K & & & & & & & & \\
\hline
\end{tabular}

9. Langkah Kesembilan

\begin{tabular}{|l|l|l|l|l|l|l|l|l|l|l|l|l|l|l|l|l|}
\hline T & R & I & N & D & U & & K & A & M & U & & J & E & L & E & K \\
\hline P & & & & & J & E & L & E & K & & & & & & & \\
\hline
\end{tabular}

10. Langkah Kesepuluh

\begin{tabular}{|l|l|l|l|l|l|l|l|l|l|l|l|l|l|l|l|l|}
\hline T & R & I & N & D & U & & K & A & M & U & & J & E & L & E & K \\
\hline P & & & & & & J & E & L & E & K & & & & & & \\
\hline
\end{tabular}

11. Langkah Kesebelas

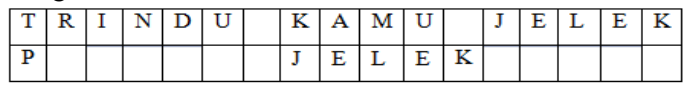

12. Langkah Keduabelas

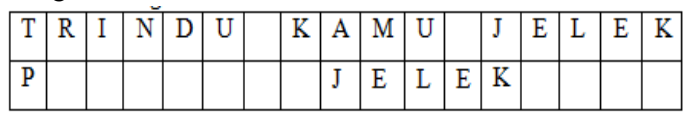

13. Langkah Ketigabelas

\begin{tabular}{|l|l|l|l|l|l|l|l|l|l|l|l|l|l|l|l|l|}
\hline T & R & I & N & D & U & & K & A & M & U & & J & E & L & E & K \\
\hline P & & & & & & & & & J & E & L & E & K & & & \\
\hline
\end{tabular}

14. Langkah Keempatbelas

\begin{tabular}{|l|l|l|l|l|l|l|l|l|l|l|l|l|l|l|l|l|}
\hline T & R & I & N & D & U & & K & A & M & U & & J & E & L & E & K \\
\hline P & & & & & & & & & & J & E & L & E & K & & \\
\hline
\end{tabular}

15. Langkah Kelimabelas

\begin{tabular}{|l|l|l|l|l|l|l|l|l|l|l|l|l|l|l|l|l|}
\hline T & R & I & N & D & U & & K & A & M & U & & J & E & L & E & K \\
\hline P & & & & & & & & & & & J & E & L & E & K & \\
\hline
\end{tabular}

16. Langkah Keenambelas

\begin{tabular}{|l|l|l|l|l|l|l|l|l|l|l|l|l|l|l|l|l|}
\hline T & R & I & N & D & U & & K & A & M & U & & J & E & L & E & K \\
\hline P & & & & & & & & & & & & J & E & L & E & K \\
\hline
\end{tabular}

Kesamaan 12,5\%, yang berhenti dan jumpa pada saat pencarian ke-16.

Algoritma boyer moore secara rata-rata proses pencarian akan menjadi lebih cepat. Sehingga pesan sebelum menampilkan "RINDU KAMU JELEK" menjadi "RINDU KAMU *****”. Penyaringan pesan maka proses berbagi pesan lebih dewasa serta merupakan salah satu tujuan penelitan dengan algoritma boyer moore .

\section{c. Algoritma Hill Cipher Pada Keamanan Pesan Teks}

Matriks $\mathrm{K}$ yang menjadi kunci harus merupakan matriks yang invertible (dapat dibalikan), yaitu memiliki multiplicative inverse $\mathrm{K}-1$ sehingga: $\mathrm{K} * \mathrm{~K}=1$. Kunci harus memiliki invers karena matriks $\mathrm{K}-1$ tersebut adalah kunci yang digunakan untuk melakukan dekripsi pesan teks. Berikut invers matriks dengan ordo 2 (2x2).

Rumus: $K=\left|\begin{array}{ll}a & b \\ c & d\end{array}\right| \cdot \mathrm{K}^{-1}=\frac{1}{|\mathrm{~K}|}\left|\begin{array}{cc}\mathrm{d} & -\mathrm{b} \\ -\mathrm{c} & \mathrm{a}\end{array}\right|=\frac{1}{\mathrm{a} \cdot \mathrm{d}-\mathrm{b} \cdot \mathrm{c}}$

Dengan:

$\mathrm{K}=$ Kunci Matrik

Penerapan Algoritma Algoritma Boyer Moore untuk Penyaringan Pesan dan Algoritma Hill Cipher dalam Keamanan 
K-1 = Invers Kunci Matrik

$\mathrm{a}=$ Nilai Baris pertama kolom pertama.

$\mathrm{b}=$ Nilai baris pertama kolom kedua.

$\mathrm{c}=$ Nilai naris kedua kolom pertama.

$\mathrm{d}=$ Nilai baris kedua kolom kedua.

Kunci hill chiper mencari invers (pembalikan) matriks:

Tentukan ordo kunci, contoh ordo $2(2 \times 2)$ :

$\mathrm{K}=\left|\begin{array}{ll}3 & 3 \\ 2 & 5\end{array}\right|$

Cari $\mathrm{K}$ invers yang menghasilkan nilai 1 bila di-mod dengan 26 maka didapat 9 x $3=27 \bmod 26,3$ merupakan bilangan prima (bilangan yang nilainya hanya dapat habis dibagi olehnya nilainya sendiri dan nilai satu).

$\mathrm{K}=\left|\begin{array}{ll}3 & 3 \\ 2 & 5\end{array}\right|=\mathrm{K}-1=\frac{1}{|\mathrm{~K}|}\left|\begin{array}{cc}5 & -3 \\ -2 & 3\end{array}\right|=\frac{1}{3.5-2.3}=9 \times \frac{1}{9}=1$

Setelah mendapat bilangan prima, maka dikali invers dengan mod 26.

$K=\left|\begin{array}{cc}5 & -3 \\ -2 & 3\end{array}\right| \bmod 26=\left|\begin{array}{cc}5 & 23 \\ 24 & 3\end{array}\right|$

Bilangan prima dikali invers dan mod 26.

$3 \mathrm{x}\left|\begin{array}{cc}5 & 23 \\ 24 & 3\end{array}\right|=\left|\begin{array}{cc}15 & 69 \\ 72 & 9\end{array}\right| \bmod 26=\left|\begin{array}{cc}15 & 17 \\ 20 & 9\end{array}\right|$

Sehingga nilai ahir didapat.

$\mathrm{K}=\left|\begin{array}{ll}3 & 3 \\ 2 & 5\end{array}\right|$ menjadi ${ }_{\mathrm{K}-1}=\left|\begin{array}{cc}15 & 17 \\ 20 & 9\end{array}\right|$.

\section{d. Enkripsi Hill Chiper Untuk Pengiriman Pesan Teks}

Misalkan, seseorang ingin mengirim pesan teks kepada temannya, dengan pesan teks "RINDU KAMU *****", pesan diambil berdasarkan pembentukan pesan yang telah dijelaskan pada submenu bab sebelumnya, pada kalimat terdapat karakter "*” merupakan karakter yang tidak terpeneuhi dengan mod 26 yaitu "aA-zZ"dan karakter "*” merupakan karakter dari penyaringan pesan, sehingga tidak perlu diamankan bertujuan untuk mempercepat proses keamanan pesan, sehingga pesan menjadi "RINDU KAMU", kunci matrik yang sama-sama telah mengetahui yaitu $\begin{array}{cc}3 & 3 \\ 5\end{array} \mid$.

Rumus: $\mathrm{C}=\mathrm{K} * \mathrm{P} \bmod 26$

Dengan:

$\mathrm{C}=$ Ciphertext

$\mathrm{K}=$ Kunci Matriks

$\mathrm{P}=$ Plaintext

Mod $=$ Modulus

Diketahui:

Kunci : $\quad K=\left|\begin{array}{ll}3 & 3 \\ 2 & 5\end{array}\right|$.

Plaintext: "RINDUXKAMU".

Proses enkripsi hill chiper dapat dijelaskan dengan perhitungan aritmatika berikut:

Ubah plaintext menjadi nilai integer berdasarkan nilai string berdasarkan nilai tabel perubahan karakter.

maka akan didapat nilai dari "RINDUXKAMU" menjadi "17 8133202310012 20". Sehingga untuk perkalian matrik dijadikan dua kolom sesuai dengan kunci matrik sehingga kolom dari nilai konrrversi keinterger adalah:

$P=\left|\begin{array}{ccccc}17 & 13 & 20 & 10 & 12 \\ 8 & 3 & 23 & 0 & 20\end{array}\right|$

Tabel 1. Perubahan Karakter

\begin{tabular}{c|c|c|c|c|c|c|c|c|c|c|c|c|}
\hline $\mathrm{A}$ & $\mathrm{B}$ & $\mathrm{C}$ & $\mathrm{D}$ & $\mathrm{E}$ & $\mathrm{F}$ & $\mathrm{G}$ & $\mathrm{H}$ & $\mathrm{I}$ & $\mathrm{J}$ & $\mathrm{K}$ & $\mathrm{L}$ & $\mathrm{M}$ \\
\hline $\mathrm{D}$ & 1 & 2 & 3 & 4 & 5 & 6 & 7 & 8 & 9 & 10 & 11 & 12 \\
\hline $\mathrm{N}$ & $\mathrm{O}$ & $\mathrm{P}$ & $\mathrm{Q}$ & $\mathrm{R}$ & $\mathrm{S}$ & $\mathrm{T}$ & $\mathrm{U}$ & $\mathrm{V}$ & $\mathrm{W}$ & $\mathrm{X}$ & $\mathrm{Y}$ & $\mathrm{Z}$ \\
\hline 13 & 14 & 15 & 16 & 17 & 18 & 19 & 20 & 21 & 22 & 23 & 24 & 25 \\
\hline
\end{tabular}

Kunci matriks dikali dangan integer (nilai karakter) dan di-mod 26 dan ubah kembali nilai integer kebentuk string dengan tabel perubahan karakter.

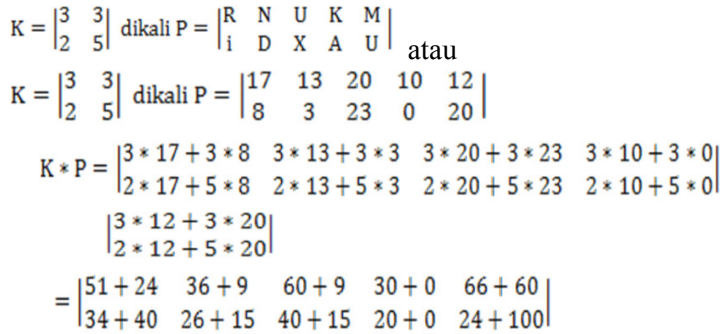




$$
\begin{aligned}
\left|\begin{array}{ccccc}
75 & 48 & 129 & 30 & 96 \\
74 & 41 & 155 & 20 & 124
\end{array}\right| \\
\mathrm{K} * \mathrm{P} \operatorname{Mod} 26=\left|\begin{array}{lllcc}
23 & 22 & 25 & 4 & 18 \\
22 & 15 & 25 & 20 & 20
\end{array}\right| \text { atau } \\
\mathrm{K} * \mathrm{P} \operatorname{Mod} 26=\left|\begin{array}{lllll}
\mathrm{X} & \mathrm{W} & \mathrm{Z} & \mathrm{E} & \mathrm{S} \\
\mathrm{W} & \mathrm{V} & \mathrm{Z} & \mathrm{U} & \mathrm{U}
\end{array}\right|
\end{aligned}
$$

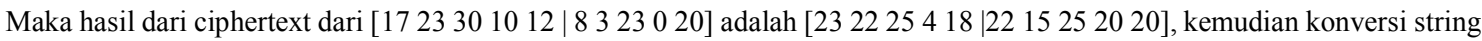
sebagai berikut "RINDUXKAMU" sehingga"XWCVZZEUSU", setelah proses enkripsi selesai maka enkripsi ditambah pesan saring yang telah dilakukan sehingga menjadi "XWCVZZUSU*****", kemudian disimpan kedalam database yang akan dikirimkan kepenerima yang telah dipilih oleh pengirim dalam pengiriman pesan.

\section{e. Deskripsi Hill Chiper Untuk Penerimaan Pesan Teks}

Setelah mendapatkan proses enkripsi dari hill chiper maka diperlukan proses deskripsi dengan hill chiper. Proses deskripsi adalah proses mengembalikan ciphertext (pesan tersandi) menjadi plaintext (pesan asli). Sehingga pesan sebelum dikirim diubah dahulu menjadi pesan tersandi.

Deskripsi dari yang telah diselesaikan pada proses enkripsi hill chiper dapat dijelaskan dengan perhitungan aritmatika berikut: Rumus : $\mathrm{P}=\mathrm{K}-1 * \mathrm{C} \bmod 26$

Dengan:

$$
\begin{aligned}
& \mathrm{P}=\text { Plaintext } \\
& \text { K-1 = Kunci matriks invers } \\
& \text { C = Ciphertext } \\
& \text { Mod = Modulus }
\end{aligned}
$$

Diketahui:

$\mathrm{K}-1=\left|\begin{array}{cc}15 & 17 \\ 20 & 9\end{array}\right|$.

Ciphertext: "XWCVZZEUSU".

Proses enkripsi hill chiper dapat dijelaskan dengan perhitungan aritmatika berikut:

Ubah ciphertext menjadi nilai integer berdasarkan nilai string.

Maka chipertext string dari "XWCVZZEUSU" menjadi integer adalah "23 $2225418 \mid 22152520$ 20", Sehingga untuk perkalian matrik dijadikan dua kolom sesuai:

$\mathrm{C}=\left|\begin{array}{ccccc}23 & 22 & 25 & 4 & 18 \\ 22 & 15 & 25 & 20 & 20\end{array}\right|$

Kunci matriks invers dikali dangan integer ciphertex dan di-mod 26 dan ubah kembali nilai integer dibentuk string dengan tabel 3.1 .

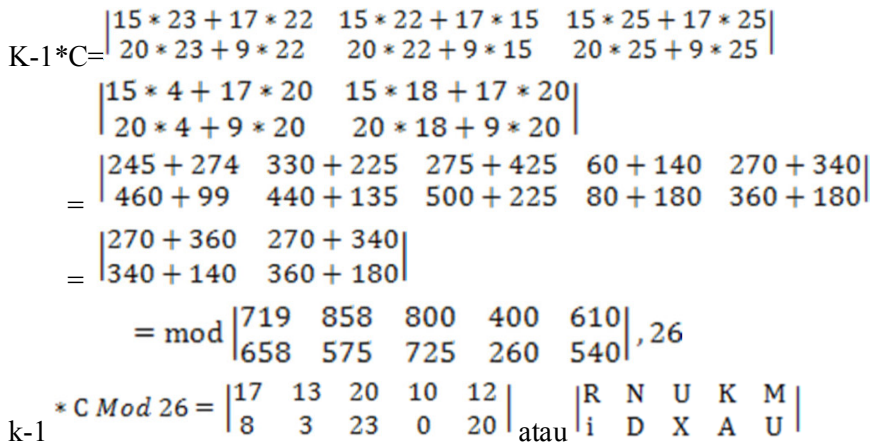

Penerima yang menerima pesan rahasia yaitu "XWCVZZEUSU" setelah memasukan kunci inver matrik [15 17;20 9] akan mengembalikan nilai ke-

plaintext yaitu "RINDUXKAMU", kemudian sistem memeriksa penganti spasi dan pelengkap karakter bila tidak genap dan menambah karakter penyaringan pesan dengan karakter "*” maka pesan menjadi "RINDU KAMU *****".

Sampai tahap ini maka proses keamananan pesan dan penyaringan pesan telah selesai dilakukan dengan perhitungan aritmatika yang dapat dipahami dan dibuktikan dengan benar.

\section{f. Implementasi}

Implementasi adalah proses penerapan dari sistem yang akan dibuat dengan tujuana berjalannya aplikakasi pada penerapan aplikasi yang telah dirancang berjalan dengan sempurna implementasi memerlukan penjelasan tentang cara kerja sistem dari awal hingga akhir. Selain itu implementasi juga sebagai langkah untuk pengujian suatu sistem apakah sistem mempunyai kekurangan, yang nantinya dari kekurangan itu akan muncul saran untuk memperbaiki sistem menjadi lebih baik.

Penerapan Algoritma Algoritma Boyer Moore untuk Penyaringan Pesan dan Algoritma Hill Cipher dalam Keamanan 77 Pesan Teks Berbasis Web Chat. Oleh : Tomy Satria Alasi 


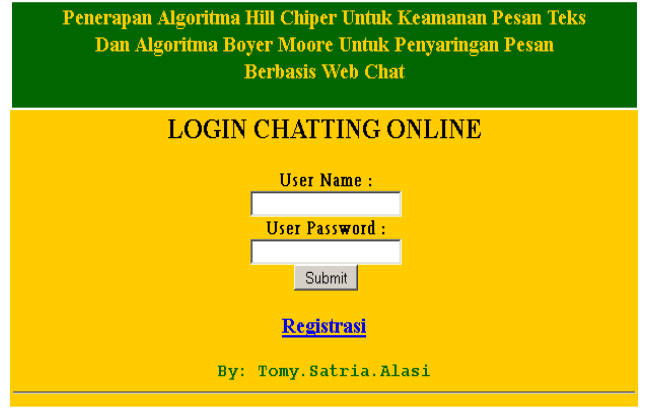

Gambar 2. Login

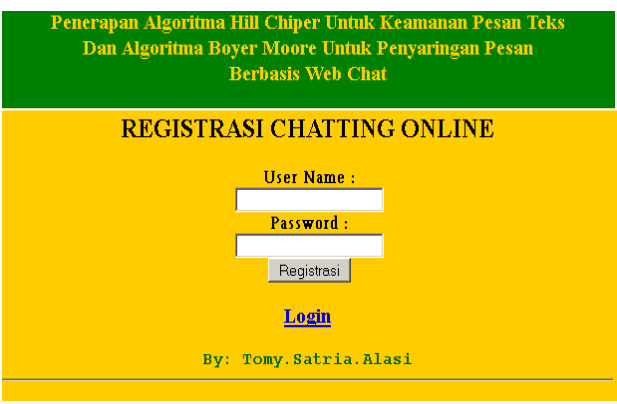

Gambar 3. Register

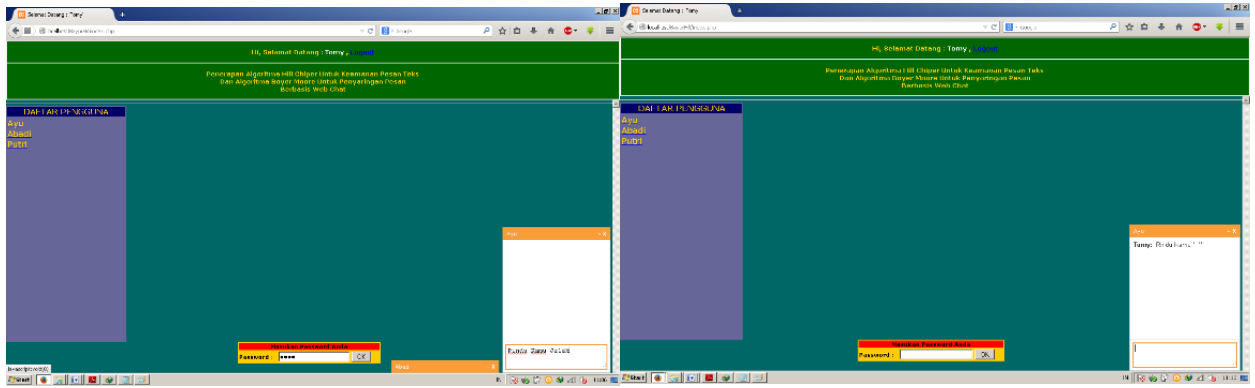

Gambar 4. Mengirim dan Menerima Pesan

\section{KESIMPULAN}

Setelah membahas dan menyajikan semua bab sebelumnya, dapat dibuat kesimpulan sebagai berikut :

1. Proses penyaringan pesan teks berdasarkan kata-kata yang tersimpan pada penyaringan pesan dengan proses pencarian true or false yaitu algoritma bayer moore dari kanan ke kiri.

2. Proses keamanan pesan teks dengan perhitungan matriks ordo dua, mod 26 dan kunci masing-masing telah diketahui oleh penerima dan pengirim yaitu berdasarkan ketetapan rumus algoritma hill chiper dengan panjang karakter 20 karakter.

3. Membangun aplikasi keamanan untuk pesan teks dengan algoritma hill chiper dan penyaringan pada pesan teks dengan algoritma bayer moore menggunakan bahasa pemrograman php dengan dukungan java script dan database MySQL.

\section{DAFTAR PUSTAKA}

[1] S. Maharani, I. Maula, and Z. Arifin, "STEGANOGRAFI VIDEO MENGGUNAKAN METODE END OF FILE (EOF),” SCAN - J. Teknol. Inf. dan Komun., vol. 11, no. 3, pp. 49-56, 2016.

[2] A. Fauzi, "Analisa Perancangan Aplikasi Penyandian Pesan Pada Email Menggunakan Algoritma Kriptografi Blowfish," MEANS (Media Inf. Anal. dan Sist., vol. 1, no. 2, pp. 72-77, Dec. 2016.

[3] S. Sutikno, I. F. Astuti, and D. M. Khairina, "Membangun Aplikasi Chatting Untuk Media Perkenalan Berbasis Web," Inform. Mulawarman J. Ilm. Ilmu Komput., vol. 13, no. 1, p. 1, 2018.

[4] F. Adinta and I. Neforawati, "Rancang Bangun Aplikasi Chatting Berbasis Web Menggunakan Docker," JOISIE (Journal Inf. Syst. Informatics Eng., vol. 1, no. 1, p. 28, 2019.

[5] D. Ariyus, "Kriptografi keamanan data dan komunikasi," Yogyakarta Graha Ilmu, 2006.

[6] H. D. M. H. Hutahaean, "Aplikasi Pembelajaran Kriptograpi berbasis Mobile menggunakan Computer Assisted Instruction," vol. 4, no. 1, pp. 2-5, 2019.

[7] R. Munir, "Kriptografi," Inform. Bandung, 2006. 
[8] A. Yudhana, S. -, and A. Djalil, "Implementation of Pattern Matching Algorithm for Portable Document Format," Int. J. Adv. Comput. Sci. Appl., vol. 8, no. 11, 2017.

[9] Z. A. Khan and R. K. Pateriya, "Multiple Pattern String Matching Methodologies: A Comparative Analysis," Int. J. Sci. Res. Publ., vol. 2, no. 7, 2012.

[10] A. Kadir, Dasar pemrograman web dinamis menggunakan PHP. Andi, 2003. 